\title{
Extreme Dynamic Responses of MW-Level Wind Turbine Tower in the Strong Typhoon Considering Wind-Rain Loads
}

\author{
Zhenyu Wang, Yan Zhao, Fuqiang Li, and Jianqun Jiang \\ College of Civil Engineering and Architecture, Zhejiang University, Hangzhou 310058, China \\ Correspondence should be addressed to Zhenyu Wang; wzyu@zju.edu.cn
}

Received 22 January 2013; Accepted 25 April 2013

Academic Editor: Massimo Scalia

Copyright (C) 2013 Zhenyu Wang et al. This is an open access article distributed under the Creative Commons Attribution License, which permits unrestricted use, distribution, and reproduction in any medium, provided the original work is properly cited.

\begin{abstract}
The damage and collapse accidents of wind turbines during violent typhoons and rainstorms have increased in recent years. To determine the dynamic response characteristics of high-power wind turbines under extreme conditions, wind load and rain load are simulated. The typhoon average wind velocity and fluctuating wind velocity are simulated by the unstable wind profile and harmony superposition method. The raindrop size distribution is simulated by the M-P spectrum, and the rain load is calculated according to the momentum theorem. A finite element model is established to study the aerodynamic responses of a wind turbine under random typhoon load and typhoon-rain loads. The maximum displacements and accelerations at the tower top and the maximum von Mises stresses at the tower bottom are calculated and compared after considering various combinations of wind direction deflections and rainfall intensities. The results indicate that instantaneous wind direction deflection has a substantial impact on the dynamic responses of wind turbines, and after introducing the effect of rain, the dynamic responses increase up to $13.7 \%$ with increasing rainfall intensities. This study has significant implications for analysing collapse accidents of wind turbines and for optimising the design of wind turbines under extreme typhoon conditions.
\end{abstract}

\section{Introduction}

Worldwide wind power has rapidly developed with the increased demand for renewable energy [1]. It can be expected that wind power will continue its fast development in the coming years. By the end of 2010, the total installed capacity of wind turbines in China had achieved $41.827 \mathrm{GW}$, ranked first in the world [2]. In wind turbine design, wind is the main external load. Because of their large ratio of height to horizontal dimension, wind turbines are more slender and more sensitive to aerodynamic loads than other structures [3]. Lavassas et al. [4] studied the static and dynamic behaviour of a $1 \mathrm{MW}$ wind turbine tower using both detailed and simplified finite element models. Murtagh et al. [5] modelled the tower and rotating blades as discretised multipledegree-of-freedom entities and used the mode acceleration method to investigate the along-wind responses of a wind turbine. Li et al. [6] analysed the aerodynamic responses of wind turbines under random wind load using the finite element method, and the results showed that the tower top displacement increased with an increase of the blades' rotational speed. Generally, current studies mostly focus on the aerodynamic responses of wind turbine towers under normal wind regimes.

In recent years, structural damage and collapse accidents related to typhoons have increased. The typhoon is different from normal wind (nontyphoon) in velocity profile, gradient height, extreme wind speed, surface roughness length, and gust factor [7]. Increasing attention has been given to the wind-induced responses of flexible structures in typhoons. $\mathrm{Xu}$ and $\mathrm{Zhu}[8]$ studied the buffeting analysis of long-span cable-supported bridges under skew winds during typhoons using a finite-element-based framework and compared those data with field measurements. Zhao et al. [9] compared the wind-excited responses of long-span bridges under normal and typhoon climate modes with time-domain FEM computations. Li et al. [10-12] conducted full-scale measurements of wind-induced responses of super-tall buildings during the passages of typhoons.

With more and more wind turbines built from land to offshore, they are at risk of damage from typhoons or hurricanes. Although few analyses are available regarding 
the aerodynamic responses of wind turbines in typhoons, visible damage to wind turbines during typhoons is reported frequently. In 2003, all six wind turbines on Miyakojima Island were extensively damaged by Typhoon Maemi [13]. On September 28, 2008, Typhoon Jangmi struck Taiwan, and one wind turbine tower located on the shore of Taichung Harbor collapsed due to strong wind and heavy rainfall [14]. When Typhoon Dujuan landed at Shanwei on September 3, 2003, the observed instantaneous extreme wind velocity in the Red Cove wind farm was $57 \mathrm{~m} / \mathrm{s}$, and 13 of 25 wind turbines ceased to operate due to serious damage [15]. Super Typhoon Saomai passed through Hedingshan wind farm of Zhejiang province in 2006, and the observed wind speed was as high as 70$90 \mathrm{~m} / \mathrm{s}$. Four units out of 28 wind turbines collapsed, and 20 units were damaged to various degrees [16]. All of these accidents seem to indicate that the practical wind profile on wind turbines may be different from the supposed ultimate limit state in the design [13]. The wind turbine is usually designed with the function that the yaw system should be locked with disk-brake when the wind speed exceeds the cut-out speed. However, the yaw system of a wind turbine could also be moved when the wind speed exceeds the cutout speed. For example, in Typhoon Maemi, the nacelles of wind turbines no. 3, 4, and 5 at the Karimata wind power plant were moved clockwise from $94^{\circ}$ to $156^{\circ}$ when the wind speed exceeded $25 \mathrm{~m} / \mathrm{s}$ [14]. As a result, they suffered larger wind load than when the blades were feathering during the typhoon. Another unfavourable wind regime occurs when the wind direction of a typhoon has sudden changes during its approach because of strong turbulent movement or local topographic effects. When Typhoon Maemi passed Miyakojima Island, the observed wind direction suddenly changed by 120 degrees [14]. In short, because of the complex factors related to wind turbine control as well as sudden changes in wind direction and wind velocity in extreme typhoon conditions, the loads on wind turbines are significantly larger than conventional design loads.

Furthermore, when a typhoon lands, it always brings a heavy rainstorm. The rain is given a horizontal velocity component by the wind, striking the wind turbines' surface along with the wind load, aggravating the vibration of the wind turbines. Some scholars have begun to consider the impact of rainfall on structures. Choi [17] observed the relationship between wind speed and rainfall intensities in thunderstorms and nonthunderstorms, which showed that under a well-conditioned model, there was little difference between wind effects on structures and simultaneous wind and rain effects. However, under an extreme climate mode, such as a thunderstorm or a typhoon, the effects of the rain load will be very great. The coupling of wind and rain is complex, but some simplified methods to calculate the simultaneous action of wind and rain loads are still valuable. Chen and $\mathrm{Wu}$ [18] used numerical simulation techniques to investigate the wind-driven rain distribution on a lowrise building. Xin et al. [19] analysed the wind-rain-induced static forces of long-span bridge decks for the simultaneous actions of wind and rain, and the results showed that rainfall can increase the wind-induced drag force on the bridge deck. Li et al. [20-22] analysed the dynamic responses of transmission line systems under strong wind-rain loads using finite element software and discovered that under the same wind speed, the effects of rainfall on structures increased with an increase of rainfall intensity. However, to the best of authors' knowledge, research on the dynamic responses and damage mechanisms of large wind turbines during strong typhoons and rainstorms is still lacking in the literature. Even though extreme typhoon and heavy rainstorm events rarely occur, their influence may be catastrophic. Thus, the dynamic responses of wind turbines under such extreme working conditions should be given more attention. After the influence of extreme conditions on wind turbines is studied and understood, design and vulnerability analyses of wind turbine tower can be developed further.

This paper mainly focuses on analysing the dynamic responses of wind turbines under extreme working conditions, especially strong typhoons, considering wind-rain loads. The unstable wind profile is used to calculate the average wind velocity of a typhoon. The typhoon fluctuating time histories are calculated by the harmony superposition method based on the Shinozuka theory, and the calculated spectrum result is in line with the trend of the target spectrum. Then, according to the M-P spectrum and the characteristics of rainfall, the rain load time histories are calculated based on the momentum theorem. In order to explore the dynamic responses on the occasion of a sudden change of wind direction, the wind-rain loads profile on the wind turbine is simulated with the blades feathering and with sudden wind direction deflections of $90^{\circ}$ and $180^{\circ}$. The effects of various rainfall intensities are also studied in the dynamic response analysis. The research results help elucidate the dynamic characteristics and failure mechanisms of wind turbines under typhoon conditions and promote a safety evaluation of wind turbines.

\section{Typhoon Wind Velocity Simulation}

2.1. Average Wind Velocity of a Typhoon. The IEC 614001 wind turbine design/safety standard gives the calculation method for wind velocity variation with height under normal wind [23]. The logarithmic wind profile $\bar{U}(z)$ can be described as follows:

$$
U(z)=\bar{U}\left(z_{r}\right) \frac{\ln \left(z / z_{0}\right)}{\ln \left(z_{r} / z_{0}\right)},
$$

where $U(z)$ is the wind speed at height $z ; z$ is the height above ground; $z_{0}$ is the roughness length; $z_{r}$ is a reference height above ground used for fitting the profile.

The calculation method for typhoon wind velocity is different from that for normal wind velocity. The existing research on various characteristics of typhoons with rough surfaces is insufficient. The Australian/New Zealand Standard [24] classifies Australia into four regions and gives each region an extreme typhoon wind velocity. According to the coefficient of wind pressure, which varies with altitude, the wind velocities at various heights can be calculated, and then the dynamic amplification factor based on the turbulence intensity can be obtained. Pang [25] believed that the range 
of typhoons should be determined first when studying the average typhoon velocity problem. He also suggested that the region within $300 \mathrm{~km}$ of a typhoon-centre be treated as a typhoon region and that the region beyond that radius be treated as a generally strong wind region. $\mathrm{Xu}$ and $\mathrm{Mu}$ [26] used the Air Pollution Model (TAPM) and exponential law to calculate the wind profile and considered the suitable power exponent to be $0.09-0.10$ if the wind speed at different heights was calculated using an exponential formula. At present, many scholars consider typhoon wind to be a steady flow; that is, the average velocity of typhoon wind does not change with time within a certain period. Chen and $\mathrm{Xu}[27,28]$ analysed typhoon characteristics using empirical mode decomposition and considered that the nonstationary wind speed can be decomposed into a deterministic time-varying mean wind speed component and a Gaussian distribution stationary random process for the fluctuating wind speed component.

In this paper, the unstable wind profile [29] is used to simulate the average wind velocity of a typhoon. The formula is as follows:

$$
\bar{U}=\left(\frac{u_{*}}{K}\right)\left[\ln \left(\frac{z-d}{z_{0}}\right)+\psi_{M}\left(\frac{z}{l_{0}}\right)\right],
$$

with

$$
\begin{aligned}
& \psi_{M}\left(\frac{z}{l_{0}}\right)=-2 \ln \left[\frac{\left(1+x_{M}\right)}{2}\right]-\ln \left[\frac{\left(1+x_{M}^{2}\right)}{2}\right] \\
& +2 \tan ^{-1}\left(x_{M}\right)-\frac{\pi}{2}, \\
& x_{M}=\left[1-15\left(\frac{z}{l_{0}}\right)\right]^{1 / 4} \text {. }
\end{aligned}
$$

Here, $l_{0}$ is the Obukhov length; $u_{*}$ is the friction velocity; $K=$ 0.4 is the Karman constant.

2.2. Fluctuating Wind Velocity Simulation of a Typhoon. The fluctuating wind is assumed to be a multivariable uniform Gaussian random process with zero-mean and composed of along-wind, across-wind, and vertical-wind components. According to the typhoon characteristics in a certain area, the proper wind spectral model can be obtained, which is the key to simulating fluctuating wind. Shi et al. [30] proposed an empirical formula for the horizontal wind velocity spectrum that does not change with altitude, according to the observed data in Shanghai from 1956. Taking into account the characteristics of the typhoon turbulence scale, which vary with altitude, at the surface boundary layer for the Shanghai district, Tian et al. [31] presented an empirical formula of horizontal wind velocity spectrum that varies with height. In this paper, the fluctuating wind velocity spectrum proposed by Hojstrup [32] is used, as shown in the following equation:

$$
\begin{aligned}
\frac{f S_{u}(f)}{u_{*}^{2}}= & 0.5 n_{\delta}\left(1+2.2 n_{\delta}^{5 / 3}\right)^{-1}\left(\frac{-\delta}{l_{0}}\right) \frac{2}{3} \\
& +105 n(1+33 n)^{-5 / 3} .
\end{aligned}
$$

Here, $n=f z / \bar{U}$ is the reduced frequency; $n_{\delta}=f \delta / \bar{U}$ is the reduced frequency with respect to the boundary layer thickness $\delta$; $f$ is the fluctuating wind frequency. Sharma and Richards [33] considered that when $l_{0}=-100 \mathrm{~m}$ and $\delta=$ $500 \mathrm{~m}$, the simulation of a typhoon is well described.

The harmonic superposition method is a standard algorithm to simulate the steady Gaussian process. Because the horizontal size of the tower is far less than the vertical size, only the vertical correlations between the calculation points are considered in this paper. Therefore, the power spectrum density function matrix of fluctuating wind can be expressed as follows:

$$
S(\omega)=\left[\begin{array}{cccc}
S_{11}(\omega) & & & \\
S_{21}(\omega) & S_{22}(\omega) & \text { Sym } & \\
\vdots & \vdots & \ddots & \\
S_{m 1}(\omega) & S_{m 2}(\omega) & \cdots & S_{m m}(\omega)
\end{array}\right]
$$

where $S_{i i}(\omega)$ is the auto-power spectrum, and $S_{i j}(\omega)$ is the cross-power spectrum, which can be calculated as follows:

$$
S_{i j}(\omega)=\sqrt{S_{i i}(\omega) S_{j j}(\omega)} \rho_{i j},
$$

where $\rho_{i j}$ is the coherent coefficient, and it uses the simplified expression proposed by Shiotani and Avai [34] as follows:

$$
\rho_{i j}=\exp \left(-\frac{\left|z_{i}-z_{j}\right|}{L_{z}}\right) .
$$

Here, $\left|z-z^{\prime}\right|$ is the spatial distance between two points in the vertical direction, and $L_{z}$ is usually 60 [35].

According to the theory presented by Shinozuka [36], the fluctuating wind velocity time histories $f_{j}(t)$ can be simulated as follows:

$$
\begin{array}{r}
f_{j}(t) \\
=\sqrt{2(\Delta \omega)} \sum_{m=1}^{j} \sum_{l=1}^{N}\left|H_{j m}\left(\omega_{m l}\right)\right| \cos \left[\omega_{m l} t-\theta_{j m}\left(\omega_{m l}\right)+\Phi_{m l}\right], \\
j=1,2, \ldots, n .
\end{array}
$$

Here, $N$ is the division number of the fluctuating wind frequency; $j$ is the number of points that are considered; $\omega=$ $\left(\omega_{u}-\omega_{0}\right) / N$ is the frequency step, with $\omega_{u}$ and $\omega_{0}$ as the upper limit and lower limit frequencies of fluctuating wind, respectively; $\omega_{m l}=(l-1) \times \Delta \omega+(m / j) \times \Delta \omega ; \Phi_{m l}$ represents the uniformly distributed random numbers in $[0,2 \pi]$. In addition, $H(\omega)$ is the Cholesky decomposition of the matrix of power spectrum $S(\omega)$, and $\theta_{j m}(\omega)$ is the argument of $H(\omega)$ as

$$
\begin{gathered}
S_{n \times n}(\omega)=H_{n \times n}(\omega) H_{n \times n}^{T}(\omega), \\
\theta_{j m}(\omega)=\arctan \left\{\frac{\operatorname{Im}\left[H_{j m}(\omega)\right]}{\operatorname{Re}\left[H_{j m}(\omega)\right]}\right\} .
\end{gathered}
$$

Here, $H^{T}(\omega)$ is the transposed matrix of $H(\omega)$, and $\theta_{j m}(\omega)$ is the ratio of the imaginary and real parts. 


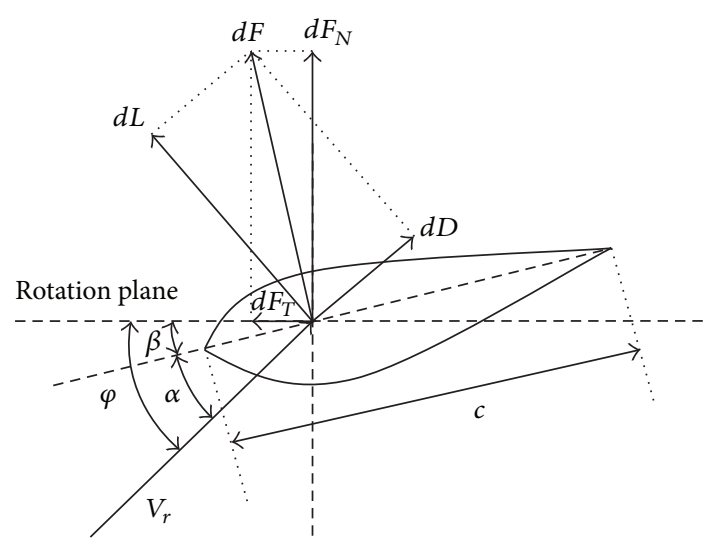

FIgURE 1: The forces on a blade element.

\section{Calculation Methods of the Wind Load}

3.1. Blade Element Theory. The wind turbine rotor is a complex aerodynamic system that extracts energy from the wind and converts it into mechanical power. To calculate the wind load acting on the blades, the blade element theory is widely used in the design and aerodynamic performance evaluation of wind turbine blades. The blade element theory assumes that the different spanwise elements are independent of each other and that the forces on blade elements are only determined by the lift-drag characteristic of the airfoil shape. The blade element theory simplifies the blade into a finite number of blade elements along the length of the blade. Therefore, the dynamic characteristics of the three-dimensional blade can be obtained by integration along the blade direction. Figure 1 shows a cross-section of a wind turbine blade [37].

The lift force $d L$ per unit length is perpendicular to the relative speed $V_{r}$ of the wind as follows:

$$
d L=\frac{\rho c}{2} V_{r}^{2} C_{L}
$$

The drag force $d D$ per unit length, which is parallel to $V_{r}$, is given by

$$
d D=\frac{\rho c}{2} V_{r}^{2} C_{D}
$$

Here, $\rho=1.25 \mathrm{~kg} / \mathrm{m}^{3}$ is the air density; $C_{L}$ and $C_{D}$ are the lift and drag coefficients of the blade, respectively; $c$ is the blade chord length. Because the forces normal to and tangential to the rotation plane are of greater concern, the lift force and drag force are projected onto these two directions, which are described by

$$
\begin{gathered}
d F_{N}=d D \sin \varphi+d L \cos \varphi, \\
d F_{T}=d L \sin \varphi-d D \cos \varphi, \\
\varphi=\alpha+\beta,
\end{gathered}
$$

where $\alpha$ and $\beta$ are the attack angle and the pitch angle, respectively.

The axial thrust acts on the tower top of the wind turbine, and the rotary moment produced by the rotary tangential force accelerates the blades. The force and moment acting on the blade can be integrated by the force and moment acting on the blade elements. The axial thrust of a blade $F_{N}$ and its moment $M_{N}$ can be calculated as follows:

$$
\begin{aligned}
F_{N} & =\int_{0}^{R} d F_{N}, \\
M_{N} & =\int_{0}^{R} r d F_{N} .
\end{aligned}
$$

The rotary tangential force of a blade $F_{T}$ and its moment $M_{T}$ can be calculated as follows:

$$
\begin{gathered}
F_{T}=\int_{0}^{R} d F_{T}, \\
M_{T}=\int_{0}^{R} r d F_{T} .
\end{gathered}
$$

Here, $R$ is the length of the blade, and $r$ is the length from the specific blade element to the root of the blade.

3.2. Calculation Methods of the Wind Load on Tower, Nacelle, and Hub. The relationship between the wind velocity and wind pressure under standard atmospheric pressure, normal temperature, and dry conditions can be obtained by the Bernoulli equation:

$$
w=\frac{1 \gamma}{2 g} v^{2} \approx \frac{v^{2}}{1630} .
$$

Here, $w$ is the wind pressure; $\gamma$ is the unit weight of air; $g=10 \mathrm{~m} / \mathrm{s}^{2}$ is the acceleration of gravity; $v$ is wind velocity. The wind load acting on the tower, nacelle, and hub can be calculated by the following equation:

$$
F=\mu_{s} \cdot A \cdot w \text {. }
$$

Here, $A$ is the projection area of the tower, nacelle, and hub surfaces perpendicular to the wind direction, and $\mu_{s}$ is the shape coefficient of the wind load.

\section{Rain Load Simulation}

There is always heavy rain associated with typhoons. The raindrops impact against the wind turbine structures with great energy, which aggravates the vibration of the wind turbines. The energy of a raindrop impact on the wind turbine structure is related to the diameter and impact speed of the raindrop [38]. Rainfall intensity is an important feature of rain, and the quantity of rainfall in one hour is taken as the rain grading standard [18], as shown in Table 1. In this paper, the dynamic results are presented only for the rainfall intensity larger than $32 \mathrm{~mm} / \mathrm{h}$.

4.1. The Distribution of the Raindrop Size. Throughout the descent process of rain, the large raindrops absorb the small raindrops, the volumes of the raindrops increase, and the shapes of the raindrops become ellipsoid. When the raindrop 
TABLE 1: The classification of rain intensity.

\begin{tabular}{lcccccccc}
\hline Classification & $\begin{array}{c}\text { Light } \\
\text { rain }\end{array}$ & $\begin{array}{c}\text { Moderate } \\
\text { rain }\end{array}$ & $\begin{array}{c}\text { Heavy } \\
\text { rain }\end{array}$ & Rainstorm & $\begin{array}{c}\text { Heavy } \\
\text { rainstorm } \\
\text { (weak) }\end{array}$ & $\begin{array}{c}\text { Heavy } \\
\text { rainstorm } \\
\text { (moderate) }\end{array}$ & $\begin{array}{c}\text { Heavy } \\
\text { rainstorm } \\
\text { (strong) }\end{array}$ & $\begin{array}{c}\text { Heavy } \\
\text { rainstorm } \\
\text { (extreme) }\end{array}$ \\
\hline Rain intensity $(\mathrm{mm} / \mathrm{h})$ & 2.5 & 8 & 16 & 32 & 64 & 100 & 200 & 709.2 \\
\hline
\end{tabular}

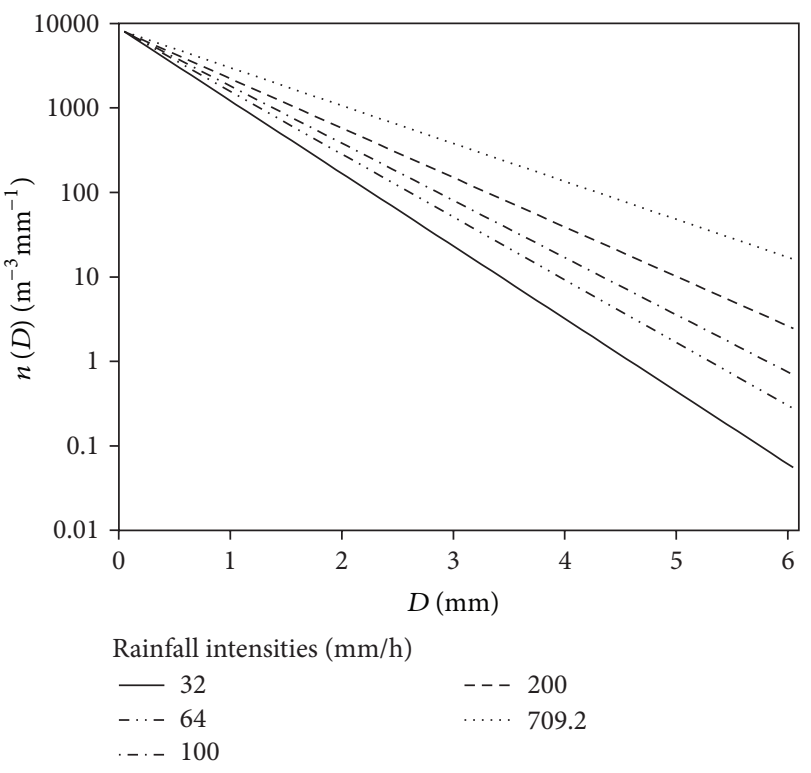

FIGURE 2: Raindrops size distribution for various rainfall intensities.

diameter increases to a certain degree, the air friction exceeds the molecular cohesion that keeps the raindrop as a whole. Then, the large raindrops split into smaller raindrops. The diameters of raindrops generally vary from $0.1 \mathrm{~mm}$ to $6 \mathrm{~mm}$ [39].

Usually the equivalent diameter (the diameter of a ball with the same volume as the raindrop) is used to describe the size of the raindrop. A large number of observations show that the raindrop size obeys a negative exponential distribution. The Marshall-Palmer exponential size distribution (referred to as M-P spectrum) is widely used $[40,41]$ as follows:

$$
n(D)=n_{0} \exp (-\Lambda D) \text {. }
$$

Here, $D$ is the diameter of the raindrop; $n_{0}=0.08 \mathrm{~cm}^{-4}$ for any rainfall intensity; $\Lambda=4.1 I^{-0.21} \mathrm{~cm}^{-1}$ is the slope factor; $I$ is the rainfall intensity. Figure 2 shows that the raindrop size distributions for various rainfall intensities are monotonically decreasing function of the size.

4.2. The Occupancy of the Rainfall in the Air. According to the raindrop size, the number of raindrops with diameters between $\left[d_{1}, d_{2}\right]$ in a unit volume of air can be calculated as follows:

$$
N(D)=\int_{d_{1}}^{d_{2}} n(D) d D
$$

where $d_{1}=0.1 \mathrm{~mm}$ and $d_{2}=6 \mathrm{~mm}$.
The volume occupancy of each category of raindrops in the rain is

$$
\alpha=\frac{1}{6} \pi d^{3} N(D)
$$

4.3. The Calculation of the Rain Load. The raindrop's velocity becomes zero very quickly when the raindrop impacts on the structure. The interaction process between the raindrops and the wind turbine structure obeys Newton's second law [22, 42]. According to the momentum theorem,

$$
\int_{0}^{\tau} \vec{f}(t) d t+\int_{V_{t}}^{0} m d \vec{v}=0 .
$$

Here, $\vec{f}(t)$ is the impact force vector of a raindrop; $\vec{v}$ is the raindrop velocity vector; $m$ is the mass of the raindrop; $V_{t}$ is the raindrop velocity before acting on the structure; $V_{t}$ is the value of the along-wind velocity at the corresponding height; $\tau$ is the time interval for the raindrop speed change from $V_{t}$ to zero.

The shape of the raindrop is assumed to be spherical in the descent process. The mass of a raindrop is $m=(1 / 6) \rho \pi d^{3}$, and $\tau=d / 2 V_{t}$ is the actuation duration. The impact force of a single raindrop on the wind turbine in a very short time interval $\tau$ can be calculated by the following equation:

$$
F(\tau)=\frac{1}{\tau} \int_{0}^{\tau} f(t) d t=\frac{m V_{t}}{\tau}=\frac{1}{6 \tau} \rho \pi d^{3} V_{t} .
$$

Here, $\rho$ is the raindrop density, and $d$ is the raindrop diameter.

The impact force of a raindrop, shown earlier, can be converted into a uniformly distributed load as follows:

$$
F_{d}=\frac{F(\tau) b \alpha}{A} .
$$

Here, $A=\pi d^{2} / 4$ is the action area of a raindrop; $b$ is the width of the structure against the rain; $\alpha$ is the volume occupancy of each category of raindrops. Substituting $A, \alpha$ into (22) yields the following equation:

$$
F(d)=\frac{2}{9} n \rho \pi d^{3} V_{t}^{2} b
$$

The impact force of rainfall on the structure can be expressed as forces in two directions: vertical and along-wind directions. In the vertical direction, $V_{t}$ is the free-fall velocity without wind. In the along-wind direction, $V_{t}$ is the wind velocity along the wind direction.

The typhoon and rainstorm sometimes occur separately and sometimes simultaneously. Similarly, the strength of the wind load and the rain load are also random. Sometimes the 
strength of the wind load is very large, but the strength of the rain is not significant, and vice versa. The distribution of the frequency and intensity of the wind and rainfall have regional meteorology characteristics whose complex mechanism is beyond the scope of this study. For a feasible and simplified structural analysis, in this paper, the wind load is the main design load of the wind turbine, and the rain load only acts as an additional load. That is, only the effect of wind and rain together is considered, and the rain load is assumed to be a uniform load. This simulation method not only can address the nature of the problem but also simplifies the calculation.

\section{Vibration Equations of Wind Turbines}

5.1. Free Vibration Analysis. The free vibration equation of the wind turbine for eigenvalue analysis can be written as

$$
M \ddot{x}+K x=0,
$$

and assuming the general form of the solutions is

$$
x=\varphi \sin (\omega t+\alpha)
$$

then the eigenvalue equation of the wind turbine can be expressed as

$$
\left|K-\omega^{2} M\right|=0
$$

where $[M]$ and $[K]$ are the mass matrix and stiffness matrix of a wind turbine, respectively; $\omega$ is the frequency; $\varphi$ is the mode shape of the wind turbine.

5.2. Dynamic Analysis of Wind Turbines. The vibration equation of a wind turbine under wind and rain loads can be obtained by the D'Alembert principle [43]:

$$
[M]\{\ddot{u}(t)\}+[C]\{\dot{u}(t)\}+[K]\{u(t)\}=\left\{F_{T}(z, t)\right\}+\left\{F_{B}(z, t)\right\},
$$

where $[M],[C]$, and $[K]$ are the mass matrix, damping matrix, and stiffness matrix of a wind turbine, respectively; $\{\ddot{u}(t)\},\{\dot{u}(t)\}$, and $\{u(t)\}$ are the time-dependent acceleration, velocity, and displacement vectors, respectively; $\left\{F_{T}(z, t)\right\}$ and $\left\{F_{B}(z, t)\right\}$ are the wind load and rain load on the wind turbine tower and blades. This paper employs the Newmark method, and the dynamic analysis is performed using the finite element software ABAQUS.

\section{Numerical Simulation Examples}

The wind turbine chosen as an example in this paper is located at a coastal wind farm in Zhejiang province, China, which uses $1.5 \mathrm{MW}$ wind turbines. According to the data observed by an anemometer tower, the maximum average wind speed over a 50-year return period for a 10 -minute time period is $23.48 \mathrm{~m} / \mathrm{s}$, the average turbulence intensity is approximately $0.173 \sim 0.128$ at the height of $10 \sim 70 \mathrm{~m}$, and the surface roughness length is 0.1432 . During the period 1949-2008, 41 typhoons struck the Zhejiang province [44].

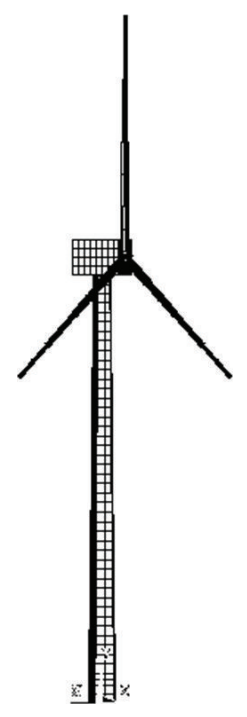

Figure 3: Finite element model of a wind turbine.

Therefore, the wind turbines will be at risk of damage from typhoons and rainstorms. The mean velocity at $10 \mathrm{~m}$ is taken as $32.7 \mathrm{~m} / \mathrm{s}$, which is the approximate wind speed of 12 typhoons.

The elastic-plastic model is established in ABAQUS to analyse the dynamic responses of the wind turbine, as shown in Figure 3. The model consists of three rotating blades connected to a nacelle, which is rigidly connected to the top of the tower [5]. The tower is modeled using shell elements while the nacelle and hub are modeled with solid elements. The connection of the nacelle and tower top is accomplished using the shell-to-solid coupling option, which allows the connection between nonconforming shell and solid models. The tower is composed of three variable crosssection steel towers for transportation and erection purposes that are bolted together by heavy flanges and bolts. The tower bottom is fully fixed at the base with no consideration of the foundation-soil interaction [45]. The main parameters of the $1.5 \mathrm{MW}$ wind turbine are as follows. The tubular tower has a total height of $63 \mathrm{~m}$ and is formed as a truncated cone with an external diameter of $4 \mathrm{~m}$ at the base and $2.7 \mathrm{~m}$ at the top and a shell thickness of $0.022 \mathrm{~m}$. The tower material is Q345E steel, and its yield stress is $325 \mathrm{MPa}$. The elastic modulus and density of the tower steel are taken as $200 \mathrm{GPa}$ and $7850 \mathrm{~kg} / \mathrm{m}^{3}$, respectively. Poisson's ratio is 0.3 , and the structural damping ratio is 0.05 . The masses of the nacelle and rotor system are $55.6 \mathrm{t}$ and $35.6 \mathrm{t}$, respectively. Furthermore, at the bottom of the tower, a substantial door opening is considered. To clearly express the entrance door direction, a coordinate system is established. The coordinate origin is taken at the centre of the tower bottom, and 0 degrees is the direction perpendicular to the rotation plain of the blades. The direction of the entrance door is shown in Figure 4. The negative influence of this opening on the wind turbine is partly counterbalanced by heavy reinforcement along its perimeter [46]. 
TABLE 2: Natural frequencies of the wind turbine tower $(\mathrm{Hz})$.

\begin{tabular}{lc}
\hline Modal number & Natural frequency \\
\hline 1 & 0.431 \\
2 & 0.432 \\
3 & 3.446 \\
4 & 3.514 \\
5 & 5.371 \\
6 & 5.627 \\
7 & 5.627 \\
8 & 7.377 \\
9 & 7.377 \\
10 & 9.030 \\
\hline
\end{tabular}

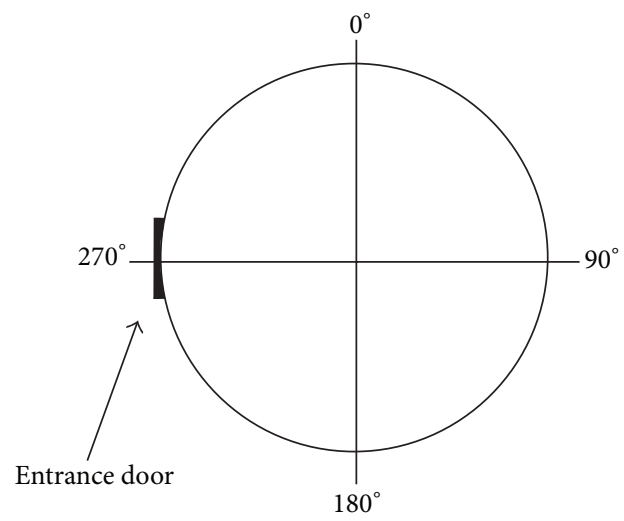

FIGURE 4: The location of the entrance door.

The blades are made of reinforced fibreglass polyester material, and the lift and drag forces are determined by the lift-drag characteristic of the airfoil shape based on the blade element theory. In the dynamic analysis using ABAQUS, the airfoil shape is simplified as equivalent rectangular cantilever beam [47], and the stiffnesses of the rectangular beam in two directions are equal to the flatwise stiffness and edgewise stiffness of the blade, respectively. The blades are attached to the hub using tie constraint where a "master" and "slave" surface is defined with all degrees of freedom for the nodes on the "slave" surface being eliminated, allowing for the two parts bonded together and no longer separate in the process of analysis. The length of each blade is $35.5 \mathrm{~m}$. The mass per unit length is assumed to vary linearly from $173.89 \mathrm{~kg} / \mathrm{m}$ at the base to $11.35 \mathrm{~kg} / \mathrm{m}$ at the tip, and the elastic modulus along the blade and chord wise are all $17.5 \mathrm{GPa}$. Table 2 presents the natural frequencies of the wind turbine tower/nacelle model. The whole model consists of 6923 elements and 8938 nodes.

6.1. The Random Wind Velocity Time Histories of a Typhoon. The unstable wind profile method put forward by Stull and the logarithm law are used to calculate the variation of the average typhoon wind velocity with altitude, as shown in Figure 5. The comparison of the two wind profiles shows that the average wind velocity calculated by the unstable wind profile method is smaller than that calculated by the logarithm law at the same height, which corresponds with

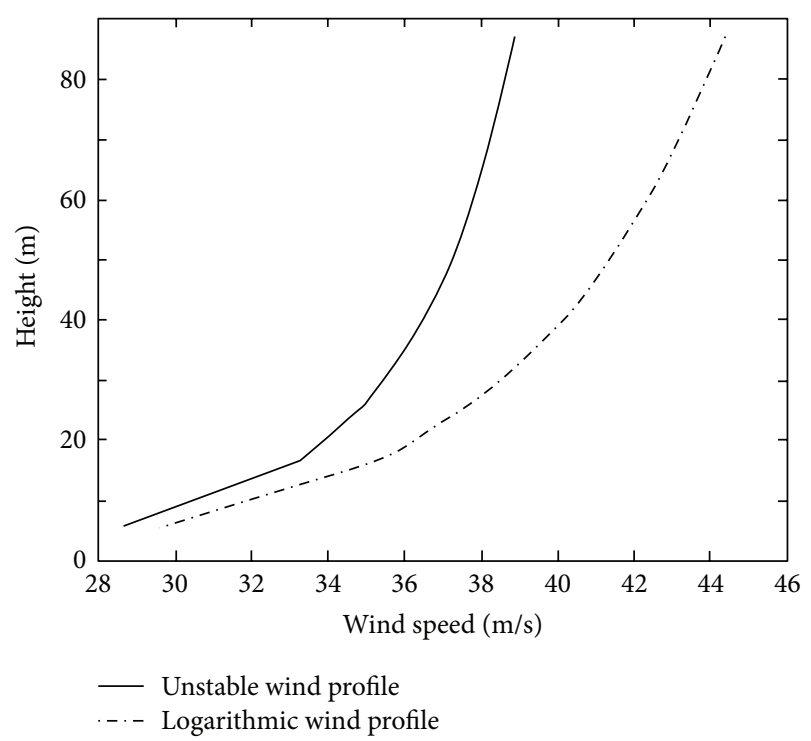

FIgURE 5: Average wind profile of a typhoon.

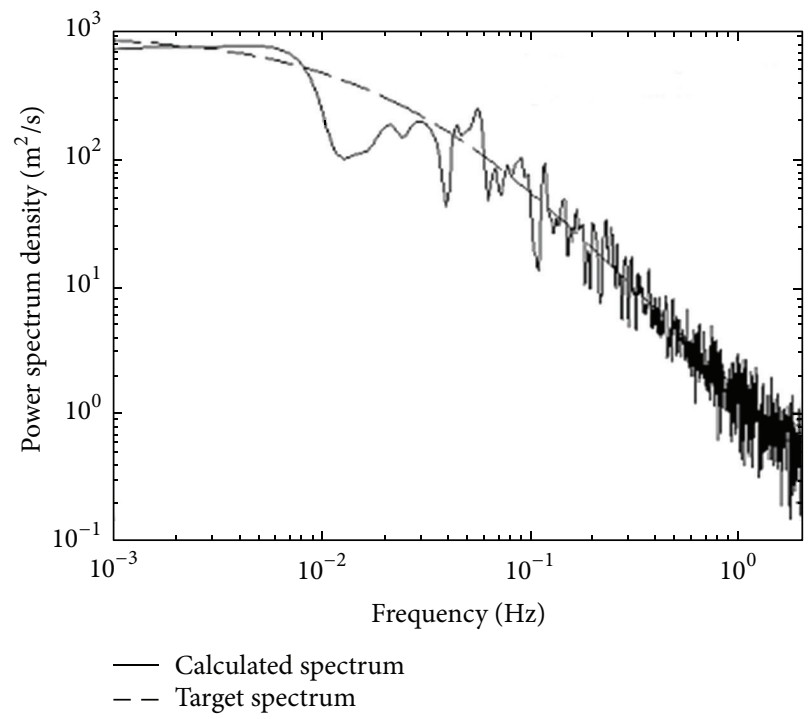

FIGURE 6: Comparison of calculated spectrum and target spectrum of typhoon fluctuating wind.

the rule that a typhoon's strong convective motion makes the upper and lower wind velocities reach unanimity.

The typhoon spectrum proposed by Hojstrup is applied to simulate fluctuating wind. To verify the simulation results, a comparison of the calculated power spectrum and the target spectrum at a height of $65 \mathrm{~m}$ is illustrated in Figure 6. Comparison of the results shows that the calculated spectrum is in agreement with the trend of the target spectrum, which verifies that the simulation is accurate. The total wind velocity time histories of each point along the height direction of the wind turbine can be attained by adding the typhoon fluctuating wind and the average wind time histories. The total typhoon velocity time histories at the tower height of 


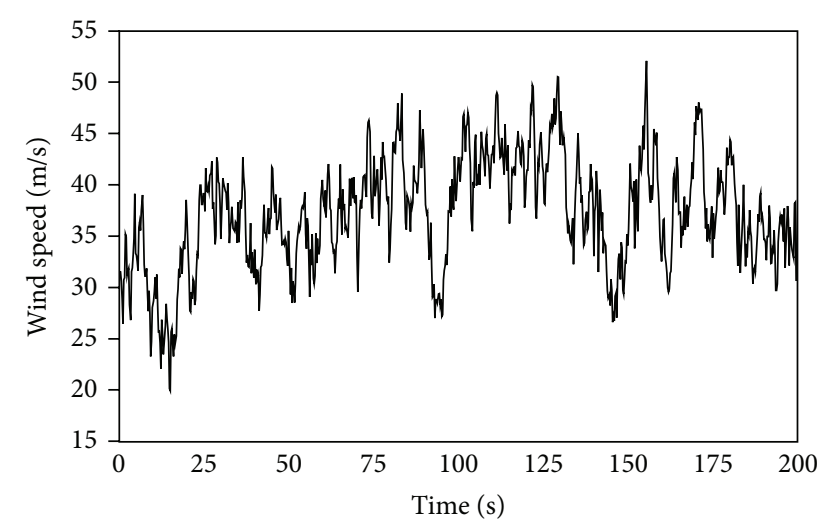

FIGURE 7: Wind velocity time history of hub on the tower.

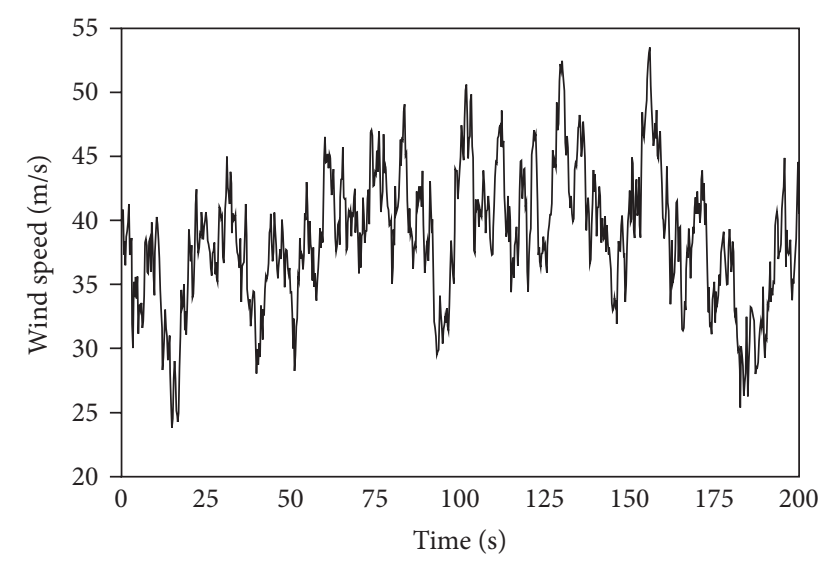

FIGURE 8: Wind velocity time history at the height of $95 \mathrm{~m}$.

$65 \mathrm{~m}$ (at the hub) and at the blade height of $95 \mathrm{~m}$ are shown in Figures 7 and 8, respectively.

6.2. Dynamic Responses of the Wind Turbine under a Typhoon Alone. In this section, the wind load on the wind turbine is calculated first. Then, the dynamic responses of the wind turbine under different conditions with the typhoon alone are calculated and compared. When the wind speed is greater than the cut-out speed of the wind turbine, the wind turbine blades stop rotating and feather. The wind direction is assumed as 0 degrees in this scenario, as shown in Figure 9(a). When the wind direction suddenly changes in a typhoon, if the nacelle cannot deflect as fast as the wind or the yaw is locked successfully, then the working conditions may appear to be different from the conventional conditions. Taking the wind direction deflections of $90^{\circ}$ and $180^{\circ}$ as examples, the relative position of the blades and the wind direction are shown in Figures 9(b) and 9(c).

6.2.1. Calculation of the Wind Load. To simplify the calculation, the tower is divided into several sections, and each blade is divided into a number of independent elements along the length. The wind load is calculated on each tower section and each blade element and then applied to the wind turbine
TABLE 3: The maximum dynamic response of the wind turbine under typhoon conditions alone.

\begin{tabular}{lccc}
\hline Working conditions as shown in Figure 9 & (a) & (b) & (c) \\
\hline Tower top response & & & \\
$\quad$ Displacement $(\mathrm{m})$ & -0.11 & 1.05 & 0.37 \\
$\quad$ Acceleration $\left(\mathrm{m} / \mathrm{s}^{2}\right)$ & 0.52 & -2.49 & 1.58 \\
Tower bottom von Mises stress $(\mathrm{MPa})$ & 48.4 & 233 & 91.7 \\
\hline
\end{tabular}

structure. Then, the dynamic responses of wind turbine can be calculated.

When the blades are feathering, the drag coefficient of the blade is 0.013 . When the wind direction has a sudden deflection of $90^{\circ}$ in a typhoon, a greater portion of the surface of the blades and nacelle will face the wind. In such a case, the drag coefficient of the blades is 1.2, and the lift force is much smaller compared to the drag force and thus can be neglected. When the wind direction has a sudden deflection of $180^{\circ}$, the drag coefficient of the blades is 0.5 . The load on each blade element is calculated according to the previously described load calculation method and then is integrated to obtain the load on the entire blades. The total wind load time histories of the three blades with the same wind velocity profile, when the blades are feathering and the wind direction has a sudden deflection of $90^{\circ}$ and $180^{\circ}$, are shown in Figures 10, 11, and 12. It can be observed that the sudden wind direction deflection has a significant effect on the load of the blades. The total wind load on the blades with a wind direction deflection of $90^{\circ}$ is several tens times greater than the wind load with a wind direction of $0^{\circ}$, although the blades are feathering nominally.

6.2.2. Dynamic Response Analysis of the Wind Turbine under Typhoon Conditions Alone. With the wind load on the wind turbine, the dynamic responses can be calculated using ABAQUS software. For comparison, the maximum tower top displacement, acceleration, and tower bottom von Mises stress are presented in Table 3 when the blades are feathering and when the wind direction has a sudden deflection of $90^{\circ}$ or $180^{\circ}$. Figures 13,14 , and 15 show the displacement, the acceleration responses at the tower top, and the von Mises stress at the tower bottom when the wind direction has a sudden deflection of $90^{\circ}$, as shown in Figure 9(b). The maximum displacement and acceleration at the tower top are $1.05 \mathrm{~m}$ and $2.49 \mathrm{~m} / \mathrm{s}^{2}$, and the maximum von Mises stress at the tower bottom is $233 \mathrm{MPa}$.

The calculation results also show that when the blades are feathering successfully, the wind direction is perpendicular to the rotation plane of the blades, and the windward face of the wind turbine blades is greatly reduced. In this case, the dynamic responses are relatively small. When the blades are feathering successfully, if the wind direction suddenly deflects $90^{\circ}$ in a typhoon, a larger surface of the blades will face the wind and suffer greater wind load. The dynamic response is the largest in this situation. If the wind direction has a sudden deflection of $180^{\circ}$ in a typhoon, the wind load on the blades only increases slightly, but the moment generated 


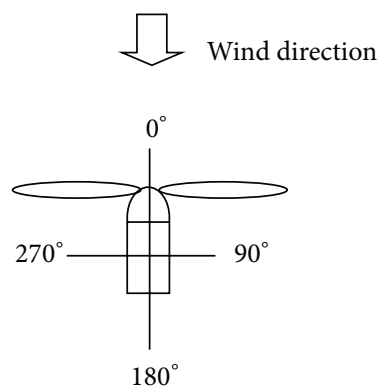

(a)

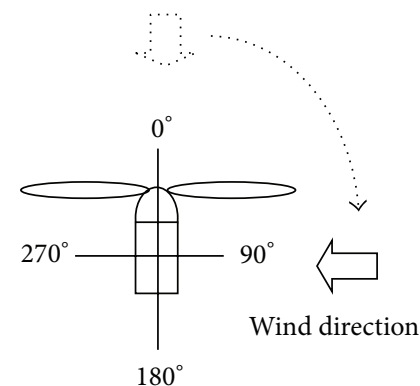

$180^{\circ}$

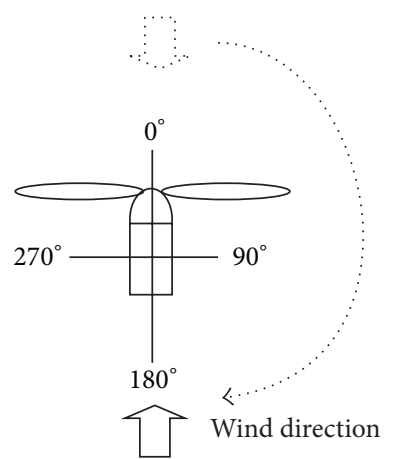

(c)

FIGURE 9: The relative position of the blades and wind direction. (a) wind direction of $0^{\circ}$ with blades feathering, (b) Wind direction deflection of $90^{\circ}$, and (c) wind direction deflection of $180^{\circ}$.

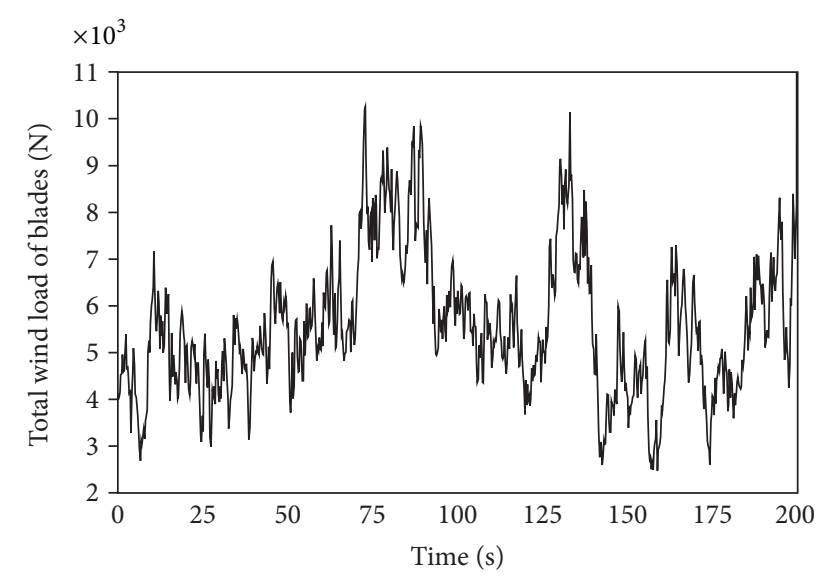

Figure 10: The total wind load time history of the blades with the wind turbine feathering.

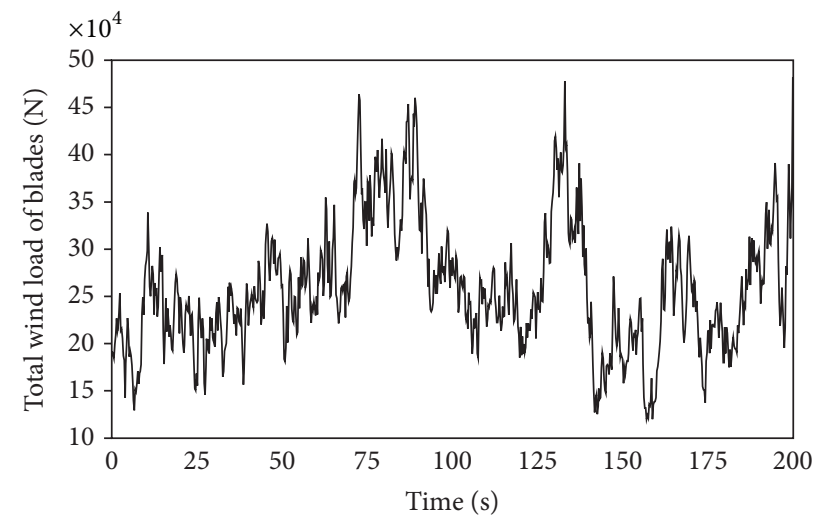

FIGURE 11: The total wind load time history of the blades with a wind direction deflection of $90^{\circ}$.

by the gravity load of the nacelle and blades will be added to that generated by the wind load in the same direction. The dynamic response of this condition is also more violent than the case in Figure 9(a).

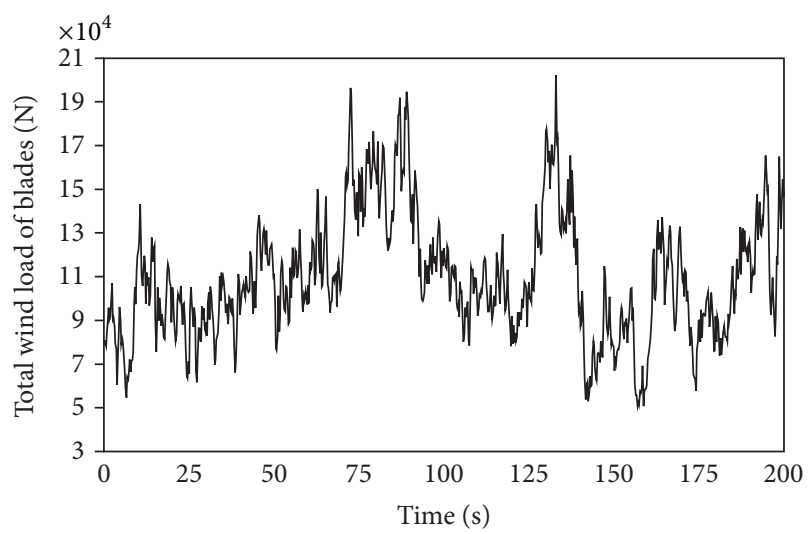

FIGURE 12: The total wind load time history of the blades with a wind direction deflection of $180^{\circ}$.

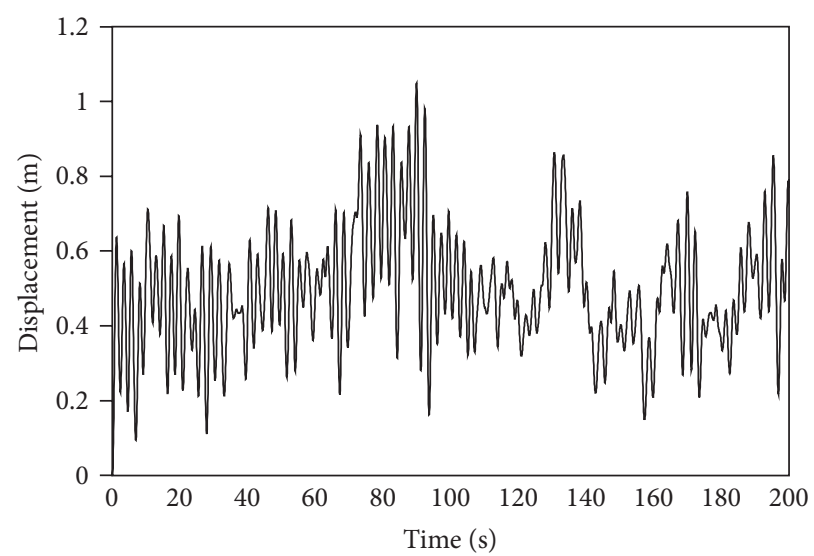

Figure 13: Displacement response at the tower top with a wind direction deflection of $90^{\circ}$.

\subsection{Dynamic Responses of the Wind Turbine under Typhoon and Rain Together}

6.3.1. Calculation of the Rain Load. Because the condition in which the wind direction suddenly deflects $90^{\circ}$ is the most 


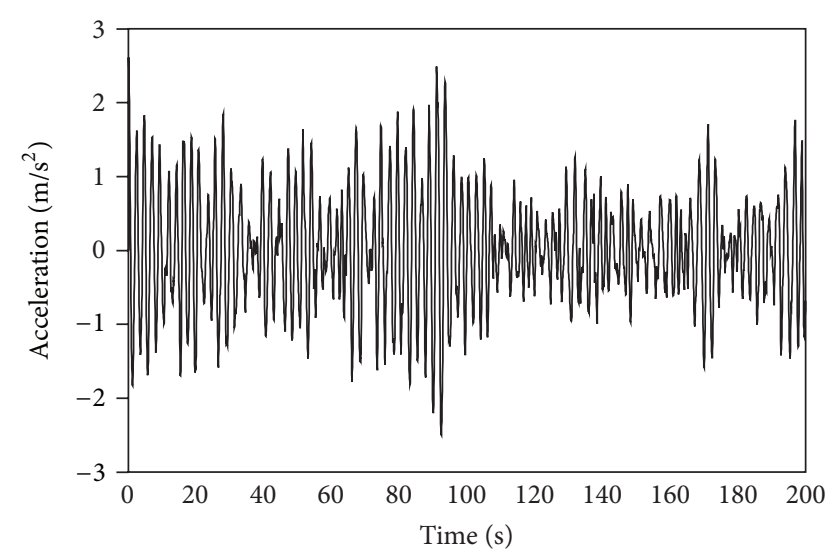

FIGURE 14: Acceleration response at the tower top with a wind direction deflection of $90^{\circ}$.

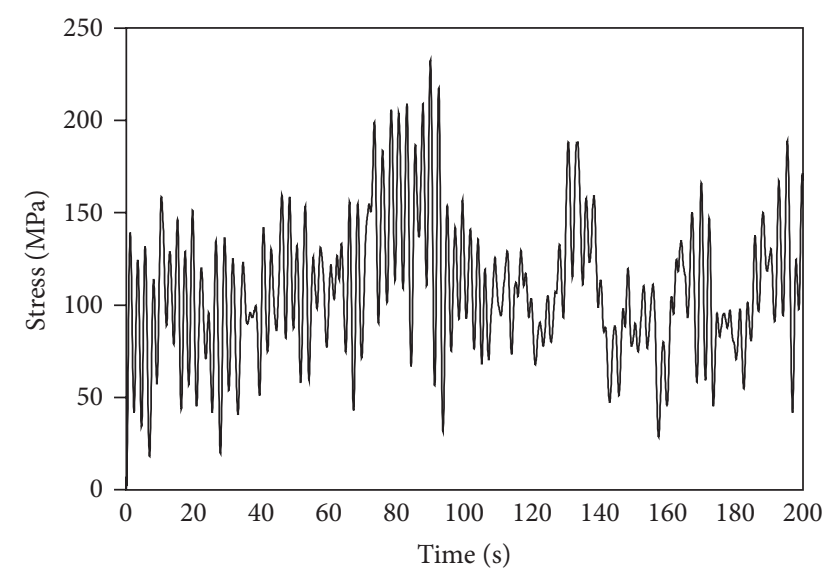

FIGURE 15: The stress at the tower bottom with a wind direction deflection of $90^{\circ}$.

unfavourable when the wind turbine is under the effect of a typhoon alone, only the responses with the combinations of various rainfall intensities and the wind direction deflection of $90^{\circ}$ are computed and compared. The time histories of the rain load per unit area of the wind turbine can be calculated by (23), and Figures 16, 17, and 18 show the total rain load time histories of the wind turbine blades under the rainfall intensities of $32 \mathrm{~mm} / \mathrm{h}, 100 \mathrm{~mm} / \mathrm{h}$, and $709.2 \mathrm{~mm} / \mathrm{h}$, respectively.

6.3.2. Dynamic Response Analysis of the Wind Turbine under Typhoon and Rain Together. To analyse the effect of rainfall intensities on the structural dynamic responses, dynamic analyses of the wind turbine are conducted for the working conditions shown in Table 4, in which working conditions $1,2,3,4$, and 5 represent the combinations of a wind direction deflection of $90^{\circ}$ and rainfall intensities of $32 \mathrm{~mm} / \mathrm{h}, 64 \mathrm{~mm} / \mathrm{h}, 100 \mathrm{~mm} / \mathrm{h}, 200 \mathrm{~mm} / \mathrm{h}$, and $709.2 \mathrm{~mm} / \mathrm{h}$, respectively. The maximum dynamic responses are presented in Table 5. The results in Table 5 are compared with the dynamic results when the wind turbine is under typhoon

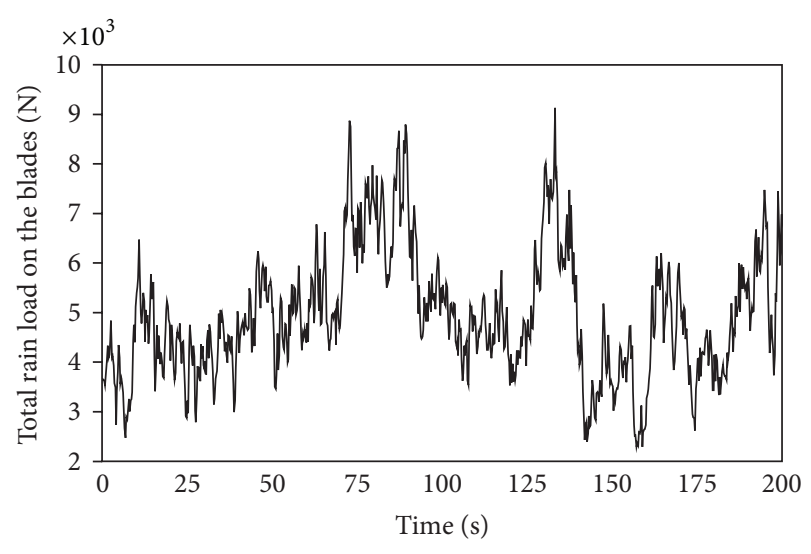

FIGURE 16: The total rain load of blades under the rainfall intensity of $32 \mathrm{~mm} / \mathrm{h}$.

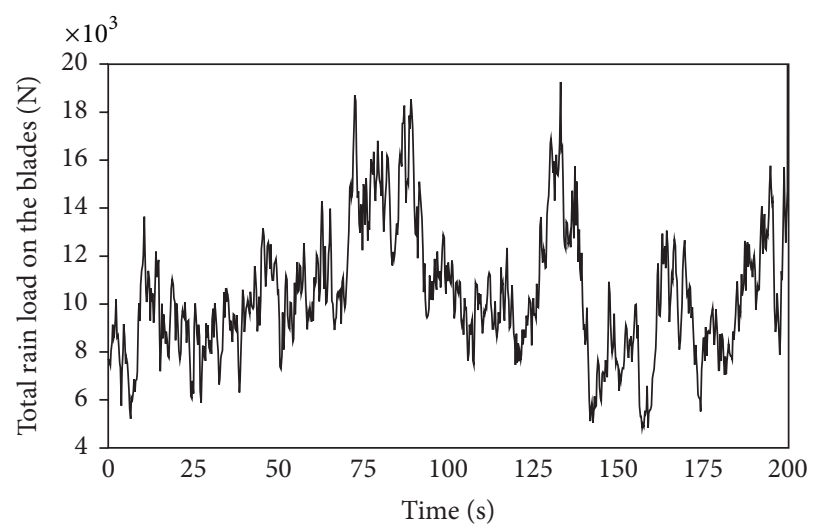

FIGURE 17: The total rain load of blades under the rainfall intensity of $100 \mathrm{~mm} / \mathrm{h}$.

TABLE 4: The combinations of a typhoon with various rainfall intensities.

\begin{tabular}{lccc}
\hline $\begin{array}{l}\text { Working } \\
\text { conditions }\end{array}$ & $\begin{array}{c}\text { Wind direction } \\
\text { deflection }\end{array}$ & $\begin{array}{c}\text { Average wind } \\
\text { speed at } 10 \mathrm{~m}(\mathrm{~m} / \mathrm{s})\end{array}$ & $\begin{array}{c}\text { Rain intensity } \\
(\mathrm{mm} / \mathrm{h})\end{array}$ \\
\hline 1 & $90^{\circ}$ & 32.7 & 32 \\
2 & $90^{\circ}$ & 32.7 & 64 \\
3 & $90^{\circ}$ & 32.7 & 100 \\
4 & $90^{\circ}$ & 32.7 & 200 \\
5 & $90^{\circ}$ & 32.7 & 709.2 \\
\hline
\end{tabular}

conditions alone with a wind direction deflection of $90^{\circ}$, and the percentage increase is shown in Table 6.

Figures 19, 20, and 21 show the displacement, the acceleration responses at the tower top, and the von Mises stress at the tower bottom when the wind turbine is under typhoon conditions with a wind direction deflection of $90^{\circ}$ and a rainfall intensity of $709.2 \mathrm{~mm} / \mathrm{h}$. The maximum displacement and acceleration at the tower top are $1.19 \mathrm{~m}$ and $2.82 \mathrm{~m} / \mathrm{s}^{2}$, respectively, and the maximum von Mises stress at the tower bottom is $265 \mathrm{MPa}$, which have increases of $13.3 \%$, $13.25 \%$, and $13.7 \%$, respectively, compared to the case with the typhoon load alone. It can be seen that the effect of the rain 
TABLE 5: The maximum dynamic responses of the wind turbine under combinations of a typhoon with a wind direction deflection of $90^{\circ}$ and various rainfall intensities.

\begin{tabular}{lcccc}
\hline Working conditions & 1 & 2 & 3 & \\
\hline Tower top response & & & & \\
$\quad$ Displacement $(\mathrm{m})$ & 1.07 & 1.08 & 1.09 & 1.12 \\
$\quad$ Acceleration $\left(\mathrm{m} / \mathrm{s}^{2}\right)$ & -2.54 & -2.57 & -2.59 & -2.65 \\
Tower bottom von Mises stress (MPa) & 237 & 240 & 242.7 & -2.82 \\
\hline
\end{tabular}

TABLE 6: The percentage increase of the dynamic responses under typhoon and rain together compared to typhoon alone with a wind direction deflection of $90^{\circ}$.

\begin{tabular}{|c|c|c|c|c|c|}
\hline Working conditions & 1 & 2 & 3 & 4 & 5 \\
\hline \multicolumn{6}{|l|}{ Tower top response } \\
\hline Displacement (m) & $1.9 \%$ & $3.0 \%$ & $3.8 \%$ & $6.3 \%$ & $13.3 \%$ \\
\hline Acceleration $\left(\mathrm{m} / \mathrm{s}^{2}\right)$ & $2.0 \%$ & $3.2 \%$ & $4.0 \%$ & $6.4 \%$ & $13.25 \%$ \\
\hline Tower bottom von Mises stress (MPa) & $1.7 \%$ & $3.0 \%$ & $4.2 \%$ & $6.7 \%$ & $13.7 \%$ \\
\hline
\end{tabular}

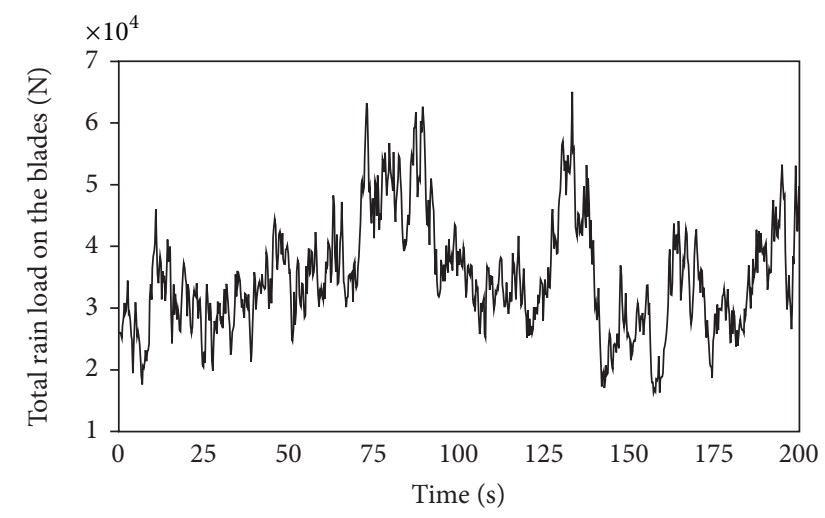

FIGURE 18: The total rain load of blades under the rainfall intensity of $709.2 \mathrm{~mm} / \mathrm{h}$.

load on the structural dynamic responses cannot be ignored and merits attention in the wind turbine design. The average wind speed of a typhoon at the height of $10 \mathrm{~m}$ is taken as $32.7 \mathrm{~m} / \mathrm{s}$ in this numerical example, and the maximum von Mises stress at the tower bottom is less than the steel yield stress. However, the instantaneous wind speed in a practical project may be higher than that adopted in this example. We can deduce that the maximum von Mises stress at the tower bottom can exceed the steel yield stress if the wind speed further increases, which most likely contributes to the collapse of wind turbines in typhoons.

\section{Conclusions}

With the development of wind power as well as the increase of extremely violent typhoon events, wind turbines are prone to be damaged due to wind-rain loads. In this paper, a dynamic analysis method for wind turbines under typhoon and rainstorm conditions is proposed. Additionally, finite element models of the blade and the wind turbine are established. The main conclusions are as follows.

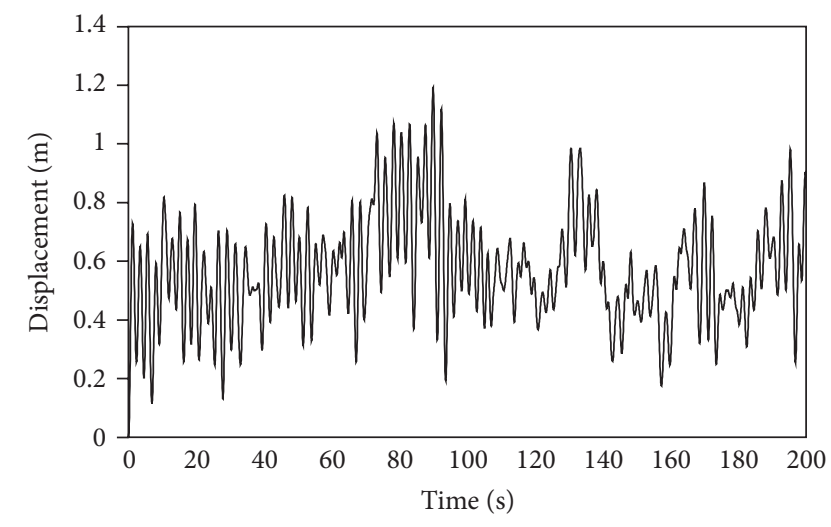

FIGURE 19: Displacement response at the tower top under the action of the typhoon and rain together.

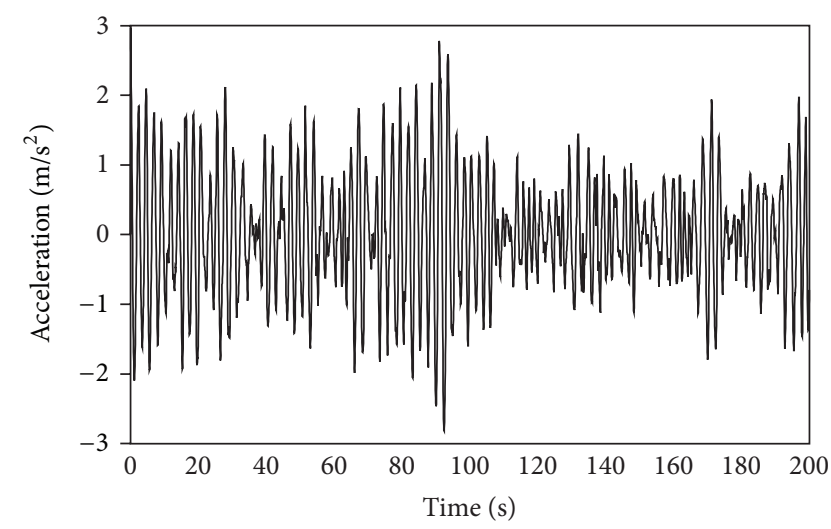

Figure 20: Acceleration response at the tower top under the action of the typhoon and rain together.

(1) The average wind velocity of a typhoon is calculated by the unstable wind profile, and the fluctuating wind is simulated by the harmony superposition method. The dynamic responses of the wind turbine are 


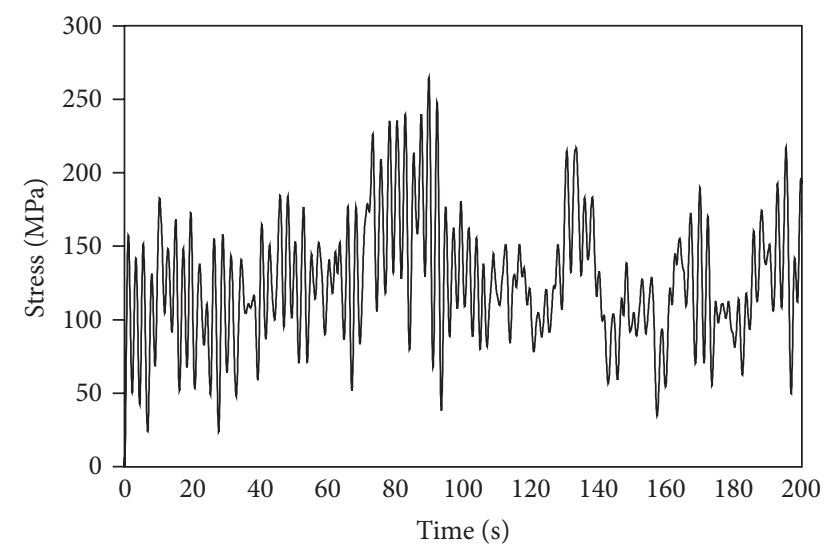

Figure 21: The stress at the tower bottom under the action of the typhoon and rain together.

calculated when blades are feathering as well as when the wind direction has a sudden deflection of $90^{\circ}$ or $180^{\circ}$ when the wind turbine blades are feathering successfully. The results show that a sudden deflection of wind direction can greatly increase both the windward area and the load on the wind turbine in a strong typhoon environment.

(2) This paper is the first to explore the rain load on a wind turbine. The raindrop size distribution is simulated by the M-P spectrum, and the rain load time history is calculated according to the momentum theorem. The calculation method of the rain load on the blades is proposed based on the blade element theory, and the combinations of a typhoon and rain with various rainfall intensities are also presented.

(3) The dynamic responses of the wind turbines increase after considering the effect of the rain load. Under the same wind velocity, the effect of the rain load on the dynamic responses of the wind turbine increases with increasing rainfall intensity. The maximum von Mises stress increased by $13.86 \%$ under the extreme condition, with a rainfall intensity of $709.2 \mathrm{~mm} / \mathrm{h}$. Therefore, the effect of the rain load on structural dynamic responses should also receive attention in wind turbine design.

(4) The feathering of wind turbine blades plays a significant role in reducing the load on wind turbines in normal wind regimes. However, under the typhoon conditions, the conventional control strategies for wind turbines may need to be improved to withstand special situations, such as sudden changes of wind direction.

\section{Conflict of Interests}

The authors declare no possible conflict of interests.

\section{Acknowledgment}

The authors gratefully acknowledge financial support from the Chinese National Nature Science Foundation (nos. 51079127, 51179171, and 51279180).

\section{References}

[1] B. K. Sahu, M. Hiloidhari, and D. C. Baruah, "Global trend in wind power with special focus on the top five wind power producing countries," Renewable and Sustainable Energy Reviews, vol. 19, pp. 348-359, 2012.

[2] J. F. Li, P. F. Shi, and H. Gao, China wind Power Outlook 2010, Hainan Publishing House, Haikou, China, 2010, (in Chinese).

[3] O. Kiyomiya, T. Rikiji, and P. H. A. J. M. van Gelder, "Dynamic response analysis of onshore wind energy power units during earthquakes and wind," in Proceedings of the 12th International Offshore and Polar Engineering Conference, pp. 520-526, Kitakyushu, Japan, May 2002.

[4] I. Lavassas, G. Nikolaidis, P. Zervas, E. Efthimiou, I. N. Doudoumis, and C. C. Baniotopoulos, "Analysis and design of the prototype of a steel 1-MW wind turbine tower," Engineering Structures, vol. 25, no. 8, pp. 1097-1106, 2003.

[5] P. J. Murtagh, B. Basu, and B. M. Broderick, "Along-wind response of a wind turbine tower with blade coupling subjected to rotationally sampled wind loading," Engineering Structures, vol. 27, no. 8, pp. 1209-1219, 2005.

[6] J. Li, J. Chen, and X. Chen, "Aerodynamic response analysis of wind turbines," Journal of Mechanical Science and Technology, vol. 25, no. 1, pp. 89-95, 2011.

[7] E. C. C. Choi, "Gradient height and velocity profile during typhoons," Journal of Wind Engineering and Industrial Aerodynamics, vol. 13, no. 1-3, pp. 31-41, 1983.

[8] Y. L. Xu and L. D. Zhu, "Buffeting response of long-span cablesupported bridges under skew winds. Part 2: case study," Journal of Sound and Vibration, vol. 281, no. 3-5, pp. 675-697, 2005.

[9] L. Zhao, Y. J. Ge, and L. D. Zhu, "Investigation of wind-induced performance about long-span bridges under typhoon climate," Zhendong Gongcheng Xuebao/Journal of Vibration Engineering, vol. 22, no. 3, pp. 237-245, 2009 (Chinese).

[10] J. R. Wu, P. F. Liu, and Q. S. Li, "Effects of amplitude-dependent damping and time constant on wind-induced responses of super tall building," Computers and Structures, vol. 85, no. 1516, pp. 1165-1176, 2007.

[11] Q. S. Li and J. R. Wu, "Time-frequency analysis of typhoon effects on a 79-storey tall building," Journal of Wind Engineering and Industrial Aerodynamics, vol. 95, no. 12, pp. 1648-1666, 2007.

[12] Q. S. Li, Y. Q. Xiao, J. R. Wu, J. Y. Fu, and Z. N. Li, “Typhoon effects on super-tall buildings," Journal of Sound and Vibration, vol. 313, no. 3-5, pp. 581-602, 2008.

[13] S. Rose, P. Jaramillo, M. J. Small, I. Grossmann, and J. Apt, "Quantifying the hurricane risk to offshore wind turbines," Proceedings of the National Academy of Sciences of the United States of America, vol. 109, no. 9, pp. 3247-3252, 2012.

[14] T. Ishihara, A. Yamaguchi, K. Takahara, T. Mekaru, and S. Matsuura, "An analysis of damaged wind turbines by typhoon maemi in 2003," in Proceedings of the 6th Asia-Pacific Conference on Wind Engineering, pp. 1413-1428, Seoul, Korea, 2005.

[15] L. X. Hong and B. Moller, "An economic assessment of tropical cyclone risk on offshore wind farms," Renewable Energy, vol. 44, pp. 180-192, 2012. 
[16] Z. Q. Li, S. J. Chen, H. Ma, and T. Feng, "Design defect of wind turbine operating in typhoon activity zone," Engineering Failure Analysis, vol. 27, pp. 165-172, 2012.

[17] E. C. C. Choi, "Wind-driven rain and driving rain coefficient during thunderstorms and non-thunderstorms," Journal of Wind Engineering and Industrial Aerodynamics, vol. 89, no. 34, pp. 293-308, 2001.

[18] S. F. Chen and X. P. Wu, "Numerical study of wind-driven rain distribution on low-rise buildings with different roof styles," in Proceedings of the International Conference on Electric Technology and Civil Engineering (ICETCE '11), pp. 3282-3285, April 2011.

[19] D. B. Xin, H. Li, L. Wang, and J. P. Ou, "Experimental study on static characteristics of the bridge deck section under simultaneous actions of wind and rain," Journal of Wind Engineering and Industrial Aerodynamics, vol. 107-108, pp. 17-27, 2012.

[20] H. N. Li and H. F. Bai, "High-voltage transmission tower-line system subjected to disaster loads," Progress in Natural Science, vol. 16, no. 9, pp. 899-911, 2006.

[21] H. N. Li and H. F. Bai, "Dynamic behavior and stability of transmission tower-line system under wind (rain) forces," Tumu Gongcheng Xuebao/China Civil Engineering Journal, vol. 41, no. 11, pp. 31-38, 2008 (Chinese).

[22] H. N. Li, Y. M. Ren, and H. F. Bai, "Rain-wind-induced dynamic model for transmission tower system," Proceedings of the CSEE, vol. 27 , no. 30 , pp. $43-48,2007$.

[23] IEC 61400-1 Ed.3, "International electro-technical commission," Wind turbines-Part 1: Design requirements, 2005.

[24] AS/NZS 1170.2, "Australian/New Zealand Standard," Structural design actions-Part 2: Wind actions, 2002.

[25] J. B. Pang, Field investigation and wind tunnel simulation of strong wind characteristics in coastal and mountainous regions [Ph.D. thesis], Tongji University, 2006, (in Chinese).

[26] J. L. Xu and H. Z. Mu, "Numerical simulation and analysis of offshore wind field features in shanghai under the influence of typhoon," Journal of Tropical Meteorology, vol. 25, no. 3, pp. 281286, 2009.

[27] J. Chen and Y. L. Xu, "On modelling of Typhoon-induced nonstationary wind speed for tall buildings," The Structural Design of Tall and Special Buildings, vol. 13, no. 2, pp. 145-163, 2004.

[28] Y. L. Xu and J. Chen, "Characterizing nonstationary wind speed using empirical mode decomposition," Journal of Structural Engineering, vol. 130, no. 6, pp. 912-920, 2004.

[29] R. B. Stull, An Introduction to Boundary Layer Meteorology, Kluwer Academic, Boston, Mass, USA, 1988.

[30] Y. Shi, W. Lu, and Y. Zhong, "The study of typhoon characteristics in the Shanghai region," in Proceedings of the second National Conference on Wind Effect, 1988, (in Chinese).

[31] P. Tian, L. Feng, and Q. Ye, "The study of typhoon wind spectrum," in Proceedings of the 2nd National Conference on Wind Effect, 1988, (in Chinese).

[32] J. Hojstrup, "Velocity spectra in the unstable planetary boundary layer (Kansas, Minnesota)," Journal of the Atmospheric Sciences, vol. 39, no. 10, pp. 2239-2248, 1982.

[33] R. N. Sharma and P. J. Richards, "A re-examination of the characteristics of tropical cyclone winds," Journal of Wind Engineering and Industrial Aerodynamics, vol. 83, pp. 21-33, 1999.

[34] M. Shiotani and H. Avai, "Lateral structures of gusts in high winds," in International Conference on Wind Effects on Buildings and Structures, 1967.
[35] X. T. Zhang, "The spatial correlations and conversion factor of wind -excited random vibration for towers and tall buildings," Journal of Tongji University, vol. 2, 1982 (Chinese).

[36] M. Shinozuka, "Simulation of multivariate and multidimensional random process," Journal of the Acoustical Society of America, vol. 49, no. 1, pp. 357-367, 1971.

[37] A. Ahlström, Aeroelastic simulation of wind turbine dynamics [Ph.D. thesis], Royal Institute of Technology, Stockholm, Sweden, 2005.

[38] M. Abuku, H. Janssen, J. Poesen, and S. Roels, "Impact, absorption and evaporation of raindrops on building facades," Building and Environment, vol. 44, no. 1, pp. 113-124, 2009.

[39] W. L. Chen and Z. L. Wang, "The trial research on the behaviours of artificial rainfall by simulation," Bulletin of Soil and Water Conservation, vol. 11, no. 2, pp. 55-62, 1991.

[40] J. Marshall and W. Palmer, "The distribution of raindrops with size," Journal of Meteorology, vol. 5, pp. 165-166, 1948.

[41] E. Villermaux and B. Bossa, "Single-drop fragmentation determines size distribution of raindrops," Nature Physics, vol. 5, no. 9, pp. 697-702, 2009.

[42] L. Gong, "Erosion calculation of raindrops' Kinetic energy of loess plateau's rainfall," Journal of Lanzhou Jiaotong University (Nature Sciences), vol. 24, no. 4, pp. 43-45, 2005 (Chinese).

[43] P. J. Murtagh, B. Basu, and B. M. Broderick, "Along-wind response of a wind turbine tower with blade coupling subjected to rotationally sampled wind loading," Engineering Structures, vol. 27, no. 8, pp. 1209-1219, 2005.

[44] W. H. Fang, X. C. Zhong, Y. Qiao, W. Lin, H. Xu, and Y. $\mathrm{Li}$, "Estimation of rural residential building vulnerability to tropical cyclone hazards by insurance claim data: case study in Zhejiang province of China," Journal of Beijing Normal University (Nature Science), vol. 47, no. 4, pp. 409-414, 2011.

[45] J. Li, J. Chen, and X. Chen, "Aerodynamic response analysis of wind turbines," Journal of Mechanical Science and Technology, vol. 25, no. 1, pp. 89-95, 2011.

[46] N. Bazeos, G. D. Hatzigeorgiou, I. D. Hondros, H. Karamaneas, D. L. Karabalis, and D. E. Beskos, "Static, seismic and stability analyses of a prototype wind turbine steel tower," Engineering Structures, vol. 24, no. 8, pp. 1015-1025, 2002.

[47] J. Li, J. Chen, and X. Chen, "Dynamic characteristics analysis of the offshore wind turbine blades," Journal of Marine Science and Application, vol. 10, no. 1, pp. 82-87, 2011. 


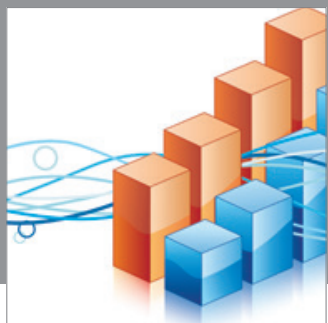

Advances in

Operations Research

mansans

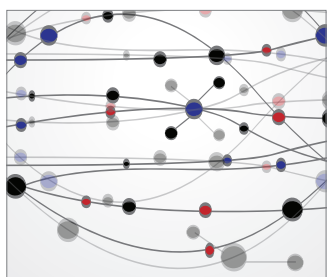

The Scientific World Journal
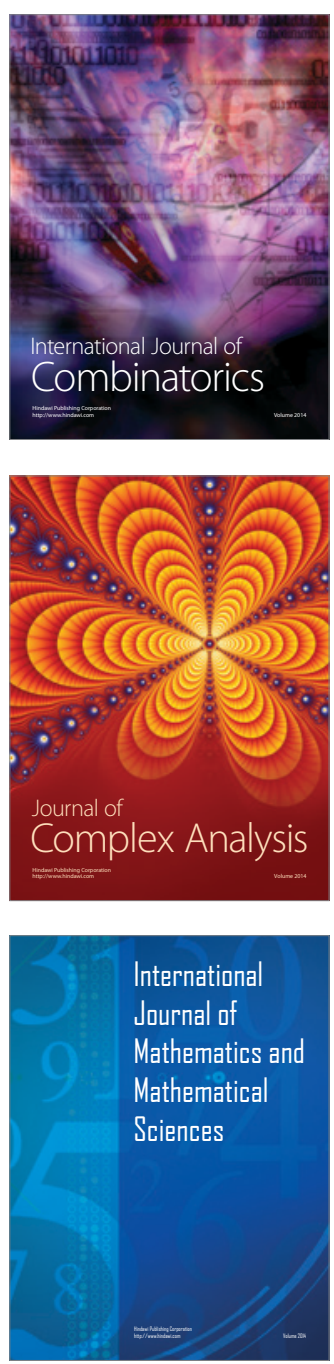
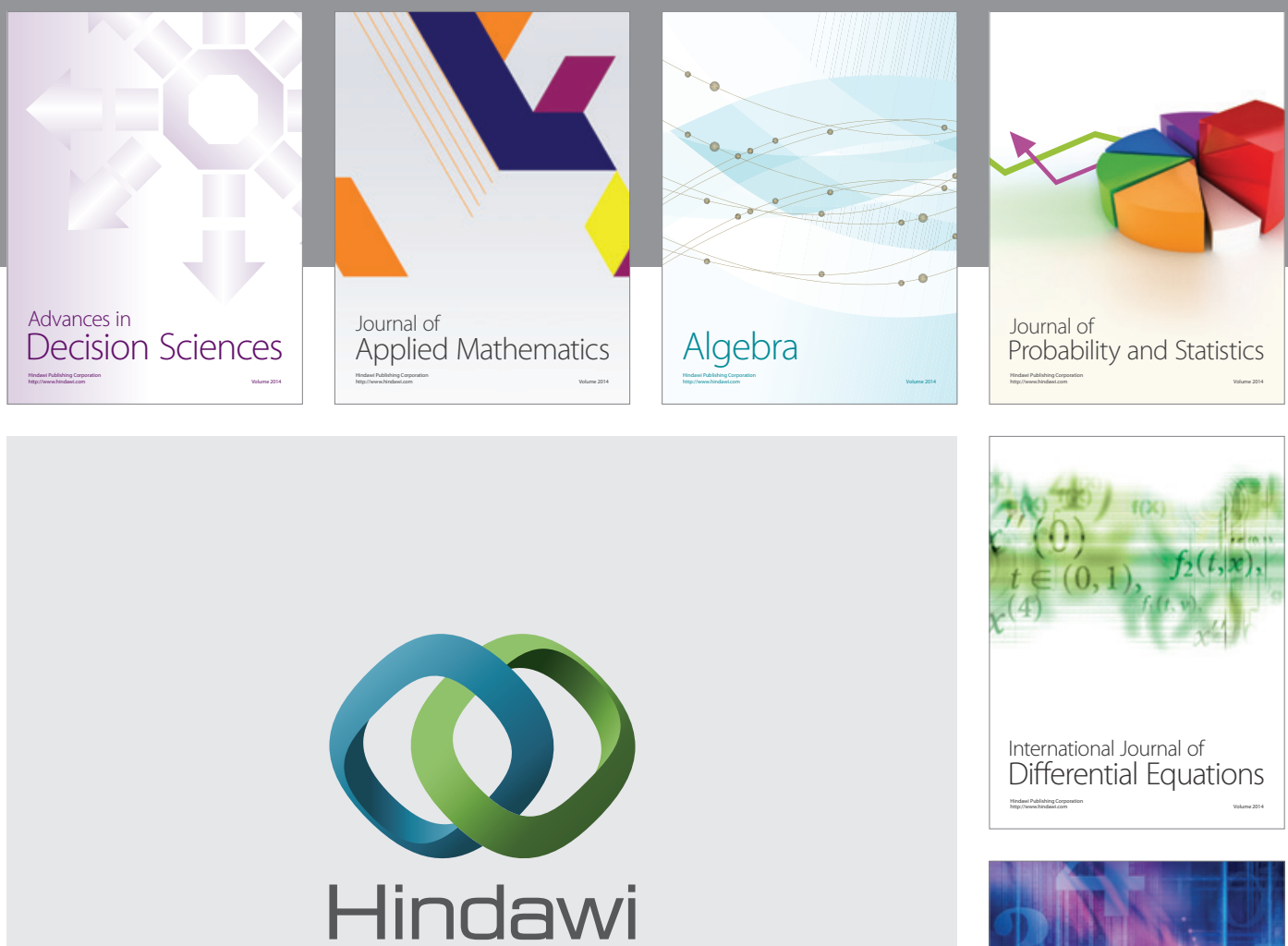

Submit your manuscripts at http://www.hindawi.com
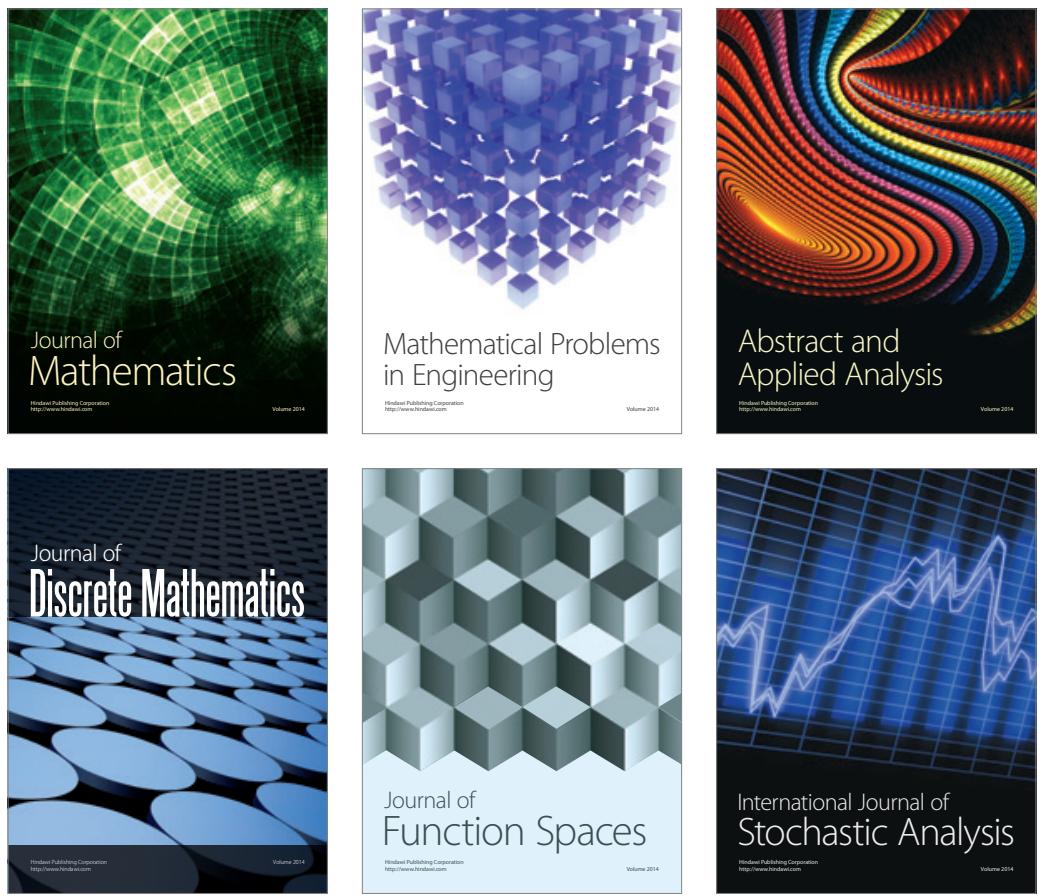

Journal of

Function Spaces

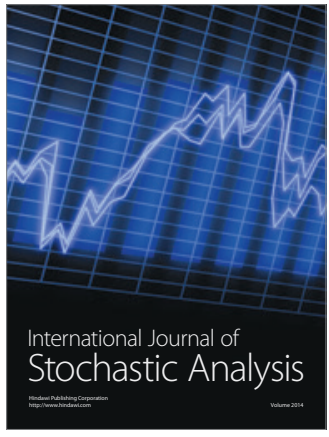

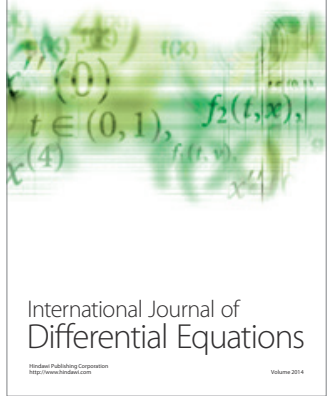
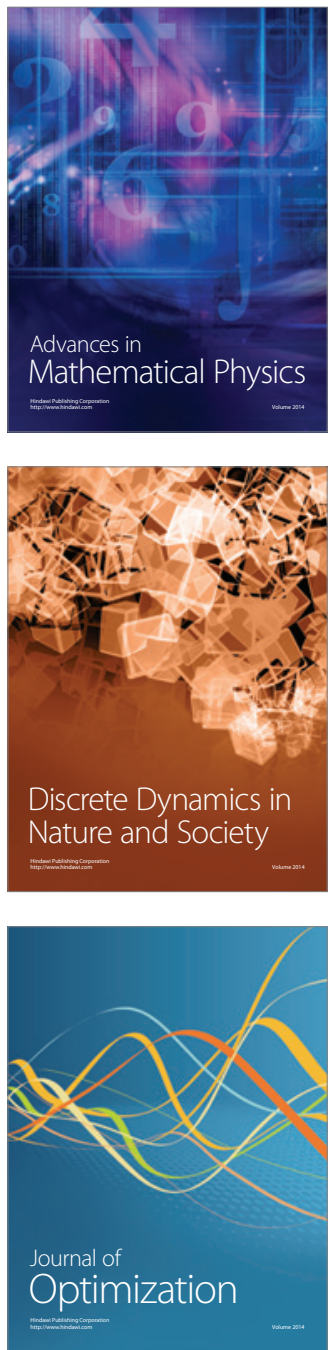